\title{
CLARICE EM CORDEL: UMA EXPERIÊNCIA LITERÁRIA NO ENSINO MÉDIO
}

\author{
Michelly Cristiny Soares \\ Mestranda em Letras (PROFLETRAS) pela Universidade do Estado do Rio Grande do Norte \\ (UERN) \\ mcristinysol@gmail.com
}

\section{RESUMO}

O presente trabalho objetivou aplicar oficinas de prática de leitura a partir do conto Bonecos de Barro reescrito em cordel. Trata-se de um estudo interventivo que segue as orientações metodológicas da pesquisa-ação de abordagem qualitativa. Foi realizado em uma turma de Ensino Médio. Tal estudo busca apresentar as diferenças e similaridades das estruturas do cânone e da literatura popular de cordéis e ressignificar nossa prática educativa, valorizando a cultura local. A fundamentação apresentada apoia-se em reflexões de concepções de Thiolent (1992), (COSSON, 2017), Lispector (1999), Leffa (1996), Todorov (2009), Solé (2009). A pesquisa permitiu compreender que a compreensão de um texto é um trabalho árduo e contínuo que, quando mediado pelo professor de forma responsiva e comprometida, pode gerar bons textos, como o cordel produzido em conjunto neste trabalho.

Palavras-chave: Clarice Lispector; cânone e popular; professor mediador; conto; cordel.

\section{RESUMÉN}

El presente trabajo, objetivó aplicar talleres de practica de lectura a partir del cuento Muñecos de Barro reescrito en cordel. Tratase de un análise interventivo que sigue las orientaciones metodológicas de pesquisa-ación de abordaje cualitativa. Fue realizado, en un grupo de Enseñanza Mediana. Tal investigación busca presentar las diferencias y similitudes de las estructuras del cánone y de la literatura popular de cordel y resignificar nuestra practica educativa valorando la cultura local. La fundamentación presentada apoyase en reflexiones de concepciones de Thiolent (1992). (COSSON, 2017), Lispector (1999), Leffa (1996), Todorov (2009), Solé (2009). La investigación permitió comprehender que la comprensión de un texto es un trabajo arduo y continuo que se fuera mediado por el profesor con responsabilidad $y$ compromiso puede generar buenos resultados como el cordel producido, en conjunto, en este trabajo.

Palabras clave: Clarice Lispector; cánones y popular; profesor mediador; cuento; cordel. 


\section{Introdução}

$\mathrm{Na}$ escola em que trabalhamos, somos colaboradores, articulando projetos que envolvem interação entre sala de aula e biblioteca. Durante um trabalho que desenvolvemos com oficinas de cordel, percebemos o interesse dos alunos pelo texto literário. Então, pensamos: por que não juntar cordel e contos? Ou melhor, o popular e o cânone? A partir dessa constatação, buscamos incentivar a leitura de clássicos e com isso, ampliar possibilidades interpretativas em forma de cordel.

Nessa direção, definimos os objetivos geral e específicos da pesquisa, conforme segue: a) analisar fatores sócio-cognitivos que contribuíssem para a formação do leitor crítico-reflexivo mediados por oficinas de práticas produtivas de cordel realizadas a partir da leitura do conto Bonecos de Barro de Clarice Lispector, b) discutir a leitura do conto em articulação com a proficiência leitora e escrita no 1 을 ano do ensino médio; c) contrastar as diferenças e similaridades das estruturas do cânone e da literatura popular, por meio da produção de cordéis e finalmente, d) ressignificar a prática educativa, através de uma metodologia de produção textual que valorize a cultura local.

A justificativa para as oficinas práticas é a possibilidade de motivar os alunos a estabelecer relações da obra escolhida por eles com o contexto social no qual estão inseridos, além de reescrever suas impressões em forma de cordel. A esse respeito, Solé (2009) já demonstrou em suas pesquisas que o leitor proficiente é capaz de estabelecer relações entre o que lê e o que faz parte do seu conhecimento interno, tendo assim o poder de transformar e adaptar a diferentes contextos de aprendizagem.

É fato que, no ensino médio, as aulas de literatura nos obrigam à leitura de diversos clássicos descontextualizados da vivência dos alunos. Refletindo sobre esse 
dilema, decidimos iniciar o trabalho com o texto clássico de forma diferente, já que não queríamos provocar estranhamento em nossos estudantes, uma vez que Cosson (2017), em suas teorias, relaciona exatamente o que queríamos abordar com os alunos, ao dizer que a literatura é atemporal por ter sua significação constituída de palavras geradas por meio das experiências do mundo que os cerca.

A parte prática consistiu em uma intervenção realizada como uma pesquisa-ação quantitativa e qualitativa de mediação de leitura iniciada por uma entrevista de grupo focal sobre lembranças de contos que os alunos escutavam na infância, seguida de uma pesquisa conjunta de contos clássicos da literatura brasileira, para que os alunos escolhessem qual autor mais se identificaria com os temas escolhidos por eles.

O corpus escolhido para análise foi a produção ficcional de Clarice Lispector. Tratase de um conto escolhido pelos alunos como representação dos clássicos que mais têm temas em comum com os temas escolhidos por eles. A partir dos temas escolhidos, foi selecionado o conto Bonecos de Barro, para a reescrita em forma de cordel.

A fundamentação apresentada apoia-se em reflexões de concepções de metodologia de pesquisa-ação de Thiolent (1992), (COSSON, 2017), Lispector (1999), Leffa (1996), Todorov (2009), Solé (2009).

\section{Procedimentos metodológicos}

O presente artigo apresenta os resultados de uma pesquisa aplicada do tipo pesquisa-ação, com abordagem quantitativo-qualitativa. Com essa metodologia, investigamos, em um primeiro momento, as razões de muitos alunos não terem interesse pela leitura de clássicos brasileiros. Com o decorrer do processo, analisamos fatores 
sócio-cognitivos que pudessem contribuir à formação do leitor crítico-reflexivo, mediados pelas oficinas de práticas de produção de cordel.

Para cumprir o objetivo da pesquisa, escolhemos uma turma de 10 ano do ensino médio composta por 32 (trinta e dois) alunos, dentre os quais 23 (vinte e três) são do sexo feminino e 09 (nove), do sexo masculino, com as idades entre 15 e 20 anos.

Para a metodologia deste trabalho, nos amparamos, com algumas adaptações, na concepção de pesquisa-ação de Thiollent (1992), como também Fonseca (2002). Escolhemos a pesquisa-ação por promover uma interação entre pesquisador-objeto de pesquisa- sujeitos investigados. Portanto, promovendo uma reflexão conjunta sobre a prática de pesquisa e os elementos que a integram (FONSECA, 2002).

Amparados nos estudos de THIOLLENT (1992) dividimos nossa metodologia de pesquisa em seis fases, as quais serão descritas nos próximos parágrafos.

\section{1a Fase: levantamento detalhado}

Nesta fase, realizamos, por meio de uma entrevista de grupo focal, um levantamento sobre a prática leitora dos alunos. Além disso, aplicamos um questionário composto de perguntas relacionadas aos hábitos de leitura de cada aluno.

\section{2a Fase: análise crítica}

Promovemos uma análise crítica sobre os possíveis problemas e pontos que poderíamos aprimorar, a fim de detectar os motivos que levaram a não leitura de clássicos, em vista de uma futura intervenção.

3a Fase: intervenção 
Nos amparamos nos resultados dos questionários aplicados, em seguida, propusemos a reescrita de algum conto infantil com elementos da atualidade que os alunos recordassem. Para finalizar, propusemos uma nova entrevista em grupo focal com dilemas enfrentados por eles enquanto adolescentes. Para casa, propusemos a pesquisa de contos clássicos da literatura brasileira que mais se identificassem com os temas gerados na entrevista aplicada.

\section{4a Fase: elaboração de documentação}

Nesta etapa, elaboramos documentos que comprovassem nossos procedimentos. Nesse contexto, nosso material de análise seria a proposta de seleção de contos de autores clássicos da literatura brasileira.

\section{5a Fase: implantação}

Embora fosse a quinta fase da metodologia de pesquisa, implantamos a partir da primeira fase, uma vez que, construímos nossa pesquisa de maneira conjunta, a partir das discussões, escolhas, seleções e análise de dados. Comungando nossas ideias entre o pesquisador e os pesquisados.

\section{6a Fase: acompanhamento}

Pretendemos, aqui, avaliar como se passou nossa pesquisa no decorrer da produção e execução de cada proposta prevista.

\section{Fundamentação teórica}




\subsection{A importância da leitura de textos literários em sala de aula}

Ao longo dos anos, tem havido um grande esforço de professores em desenvolver nos alunos o gosto pela leitura de clássicos literários brasileiros. No entanto, mesmo que o estudo literário seja importante, ao conhecimento do aluno, utilizar desse artifício com o intuito de formar um sujeito-leitor, está cada vez mais difícil, "é preciso tomá-lo no sentido amplo e intenso que prevaleceu na Europa, até fins do século XIX, e que hoje é marginalizado, quando triunfa uma concepção absurdamente reduzida do literário" (TODOROV, 2009, p. 76).

A concepção reduzida do literário citada por (TODOROV, 2009) se traduz à leitura de clássicos no ensino médio, por meio de críticas de livros clássicos inseridas nos livros didáticos, ou, até mesmo, da obrigatoriedade da leitura de livros cânones, sem nem mesmo uma preparação prévia do aluno. No entanto, o gosto pela leitura deveria estar intrínseco à vida do estudante, visto que seu contexto é repleto de referências literárias que podem partir da oralidade, da vivência ou do material utilizado na escola.

Compreendendo que a inserção do texto literário na vivência do estudante é de suma importância, Rangel (2003) reconhece ser indispensável, quando trata-se da formação e do gosto literário do aluno. Somado a essa declaração, o autor continua enfatizando que se deve destacar a importância cultural e pedagógica na escola para uma formação efetiva do leitor, já que, segundo o autor, "não se pode deixar em segundo plano a história e características dos cânones" (RANGEL, 2003, p. 138).

Nesse sentido, a leitura tem o papel de conscientizar o leitor a fazer questionamentos sobre a realidade em que está inserido (LAJOLO, 1996), ademais, é uma arma de fundamental transformação do ser social, podendo provocar o desenvolvimento 
de aspectos cognitivo, de memória e de percepção da realidade que poderão ser transformados e repensados, criando um leitor crítico-reflexivo.

\subsection{Contextualizando os gêneros - cordel e conto}

\subsubsection{Cordel}

Cordel vem da palavra cordão, livreto pequeno que já foi chamado de folheto. De origem europeia, mais recorrente no Nordeste, hoje está espalhado pelo Brasil. Sobre esse gênero Nogueira (2012) afirma:

a literatura de cordel é uma forma cultural híbrida e intrincada que resiste às interpretações fáceis que a veem como um gênero rígido e substantivo, simples literatura de evasão ou literatura de rua. Apesar da hesitações e indefinições de diversos tipos que lhe são características, esta literatura assume um importante papel na codificação das aquisições comunitárias, uma função conjuntamente literária e identitária (NOGUEIRA, 2012, p. 697).

A aproximação com o gênero cordel pode despertar no aluno o reconhecimento de aspectos do cotidiano com os temas desenvolvidos no texto. Uma vez tendo esse reconhecimento, se torna mais latente a possibilidade da reescrita de contos em forma de cordel, destacando os pontos a serem abordados. Outro fator relevante é a contribuição do cordel na formação do aluno. O uso desse gênero possibilita o conhecimento de outros conteúdos. Além de poder despertar no aluno o interesse por leitura e produção de poemas. 
Sendo assim, o cordel pode contribuir para a formação do sujeito como um todo. As experiências culturais presentes nos cordéis vêm se adaptando e sobrevivendo aos novos contextos socioculturais, pois, de uma certa maneira, a realidade costuma ser retratada nos poemas. (MARINHO; PINHEIRO, 2012). Embora a afirmação dos autores seja real, o cordel vem perdendo sua importância com o passar do tempo. Cabe a escola, mais diretamente ao professor de literatura, resgatar o valor das contribuições do cordel na formação do conhecimento do discente.

\subsubsection{Conto}

O homem tende a procurar explicações para questões que ele não saberia explicar de forma racional. Nesse contexto, surgiu o conto de fadas, primeiramente em forma de narrativas para adultos, depois, com os irmãos Grimm, como narrativas fascinantes escritas para "disciplinar" as crianças. "O conto de fadas a cada geração é descoberto e volta a encantar leitores e ouvintes de todas as idades" (COELHO, 2004, p. 21).

Já na primeira infância, o homem tem consciência que a história pode ser determinante à formação da personalidade do ouvinte. Nesse aspecto, o conto infantil é relevante à consciência da criança, quando se trata de aquisição de valores, como respeito, moral, honestidade. "O valor real da história é ser instrumento educativo e, deste ponto de vista, atende às necessidades humanas em todos os seus aspectos" (CHAVES, 1963, p. 21).

A linguagem nos permite interagir em um contexto social. Nesse aspecto, o sujeito adequa seu discurso a cada momento de sua comunicação, de acordo com sua necessidade. Em relação à afirmação sobre linguagem BRONCKART (2003) afirma que 
para existir aprendizagem, deve haver interação com o outro, uma vez que, "os textos são produtos da atividade humana e, como tais, estão articulados às necessidades, aos interesses e às condições de funcionamento das formações sociais no seio dos quais são produzidos" (BRONCKART, 2003, p. 72).

\subsection{Uma perspectiva de trabalho prático}

Clarice Lispector foi a autora que os alunos escolheram para rescrever versões dos contos em cordel. Segundo eles, dentre os textos lidos, os de Lispector foram os que mais refletiram os anseios e problemáticas vividas na realidade de um adolescente.

Ao ler a obra de Clarice, o leitor além de poder se deparar com as impressões refletidas pela autora sobre aspectos da realidade, também consegue perceber que sua obra se desenvolve, oscilando em nuances que podem passar pelo científico, mítico, místico, de forma poética e introspectiva.

Dentro desse panorama, se faz importante a discussão da leitura de clássicos da literatura brasileira articulada à vivência dos estudantes para, assim, conseguir ressignificar o sentido de literatura na concepção do discente e na prática educativa, para isso optamos pela reescrita em cordel do conto Bonecos de Barro.

\section{Análise dos resultados das oficinas}

\subsection{Aspectos de estrutura e rima}


Para a análise dos dados, nos baseamos na estruturação desenvolvida pelo tipo narrativo. Para Roulet (1999), a estrutura narrativa em linhas gerais corresponde a cinco fases: estado inicial, complicação, reação, resolução e estado final. Em outras palavras: introdução, desenvolvimento e conclusão. Nesse sentido, analisamos a produção dos alunos em um primeiro momento, em relação à estrutura narrativa.

No cordel analisado, destacamos a contemplação de quatro critérios de avaliação narrativa: enredo, desfecho, estrutura e rima. Pinto (2015) afirma que o cordel é uma estrutura que deve ter métrica, sequência textual que consistente em começo, meio e fim. Atentando para continuidade narrativa para que a história não fique sem sentido.

No que se refere à estrutura do cordel, Abreu (1999, p. 87) a define como sendo

a regularidade um auxiliar mnemônico poderoso: assim, a existência de um padrão para a estrutura estrófica, rítmica e métrica é uma ferramenta fundamental. Os padrões fixos auxiliam fortemente a composição dos poemas, atuando como um arcabouço organizador da produção: quando não se pode contar com o apoio do papel, quando não se pode revisar e reescrever, é mais operacional preencher uma estrutura já conhecida do que criar "livremente".

\subsection{Aspectos metacognitivos}

Cada parte do cordel baseado no conto Bonecos de barro foi produzida por um grupo de alunos da sala de forma coletiva. O texto Bonecos de barro, de Clarice, é tão intenso como muitas outras obras da autora. Assim, pretendemos que durante a reescrita do texto os alunos possam ativar fatores sócio-cognitos que contribuam para sua análise crítica.

Em uma primeira leitura, Bonecos de barro parece tratar de um conto simples, 
com uma menina simples que faz bonecos simples. No entanto, ao lê-lo mais atentamente começamos a perceber a profundidade psicológica que é marca da autora.

\author{
BONECOS DE BARRO \\ I \\ Saudades da menina Clarice \\ De suas histórias sem noção \\ Histórias surpreendentes \\ Falavam de amor, fé e traição \\ Menina estranha de se olhar \\ Mas tinha um bom coração
}

O cordel inicia-se enfatizando os sentimentos conturbados que os autores sentem por Clarice, destacando algumas características da autora em sua obra. No livro Aspectos da leitura, Leffa (1996) conceitua o que seria o processo de metacognição:

\begin{abstract}
A metacognição na leitura trata do problema do monitoramento da compreensão feito pelo próprio leitor durante o ato da leitura. O leitor, em determinados momentos de sua leitura, volta-se para si mesmo e se concentra não no conteúdo do que está lendo mas nos processos que conscientemente utiliza para chegar ao conteúdo (LEFFA, 1996, p. 46).
\end{abstract}

Nesse aspecto, a primeira estrofe expressa o sentido da metacognição quando se trata da contribuição à formação do leitor crítico-reflexivo em relação a produção do cordel, uma vez que os alunos se concentraram no que leram e conseguiram refletir sobre seu processo de escrita e leitura. Segundo eles a obra de Clarice é ao mesmo tempo estranha e surpreendente.

Além disso, conseguem compreender os temas que Clarice tratava (amor, fé, traição). Finalizam traduzindo suas impressões pela própria autora do conto original menina estranha de se olhar, mas com grande coração. 
II

Sua casa era humilde

E tinha um calçadão

Ela vivia lá fora

A pensar numa criação

Sentada junto à janela

E contou mais um prosão

A segunda estrofe é constituída de uma extensão. Nesse sentido, a percepção dos alunos passa de um simples gosto pelas histórias de Clarice a uma introdução ao conto Bonecos de Barro. Nesse ponto, os alunos abordam a condição de vida da personagem. Enfatizando a condição da casa humilde, mas com um calçadão no qual a personagem ficava sentada pensando em sua criação.

III

Caminhava até a estrada

À procura de barro perfeito

Chegou lá na cachoeira

O norte batia no peito

Encheu a saca de barro

Saiu andando ao estreito

Os alunos iniciam a terceira estrofe, descrevendo a trajetória que a personagem enfrenta, até conseguir a matéria prima da produção de seus bonecos. No processo de construção do cordel, os leitores/autores, passaram de meros leitores inconscientes do processo de atividades cognitivas a protagonistas ativos da construção do domínio das atividades da construção do texto.

IV

Gosto de suas histórias 
E uma chamou-me atenção

Foi quando sentou na calçada

E fez um boneco ilusão

Usou água e barro molhado

Deu-se a realização

Ao avaliar os processos de transformação, os autores fazem uso de fatores sóciocognitivos, com isso, contribuindo à formação do leitor crítico-reflexivo. "A leitura rápida e fácil, concentrada no conteúdo, é uma atividade cognitiva. A descoberta de que houve um problema e de que uma correção no rumo da leitura precisa ser feita para recuperar o texto é uma atividade de metacognição" (LEFFA, 1996, p. 49).
$\mathrm{V}$
Depois de pronto os bonecos
Colocou-os lá no solzão
E nas quatro horas da tarde
Pegou a sua invenção
Pintou com diversas cores
E brincou com ela no chão

De acordo com Leffa (1996), a compreensão é percebida como um processo global. Nesse ponto, os autores do cordel conseguiram compreender e expressar sentidos que estavam bem além do texto original. Ao selecionarem vocábulos do conto que tivessem a faculdade de chamar a atenção do leitor, os alunos conseguiram, com criatividade, construir rimas com a possibilidade de comunicação entre leitor e escritor.

\footnotetext{
VI

Depois de seco os bonecos

Houve uma transformação

Eles tomaram vida

Foi grande a satisfação

Surpreendeu-se a menina
} 


\title{
Com a grande criação
}

Nessa estrofe, os alunos fazem referência ao fato dos bonecos criarem vida por meio da metamorfose, ou seja, a transformação de barro em boneco. Junto a isso, há o destaque da surpresa de Virginia ao perceber que sua obra criou vida. Por conseguinte, constituíram na poesia um novo significado enfatizado pela personagem do conto original, a qual conseguia por meio da sua arte de construir bonecos expressar seus sentimentos por meio de uma prática de criar "vida" com as próprias mãos.

Portanto, "o sujeito não tem apenas consciência do resultado da tarefa, mas também consciência do processo que deve seguir para chegar ao resultado" (LEFFA, 1996, p. 49).

\author{
VII \\ De Clarisse, é esse meu conto \\ Encerro agora o meu prosão \\ Espero que tenha gostado \\ Porque não foi fácil não \\ Sou quadrado e nordestino \\ E meu falar é do sertão.
}

Os alunos encerram seu cordel fazendo referência ao público leitor, sem deixar de enfatizar que seu trabalho de rima foi árduo, em seguida, expressam o desejo de terem agradado, como também não deixam de imprimir no texto suas próprias características de quadrados, nordestinos, mas com grande coração. "Uma das características fundamentais do processo de leitura é a capacidade que o leitor possui de avaliar a qualidade da própria compreensão" (LEFFA, 1996, p. 45).

No processo de metacognição, o leitor eficiente sabe identificar quando está tendo problemas ou avançando. Nesse sentido, o leitor consegue refletir sobre sua 
própria compreensão, podendo, com isso, avaliar seu processo de desenvolvimento da habilidade leitora (LEFFA, 1996). Ao finalizarem o cordel, os alunos conseguiram refletir sobre eles como seres imperfeitos, além de enfatizarem a dificuldade que tiveram durante a produção do cordel.

\section{Em que resultou}

Foram realizadas o total de cinco oficinas, com duração entre duas e quatro aulas de 50 minutos. Na primeira tivemos a parte de conscientização e exploração do assunto, seguida da tempestade de ideias, práticas de produções culminando com o projeto realizado.

As produções finais dos alunos, foram expostas em um cordel na sala de aula. Convidamos a equipe da biblioteca e a equipe pedagógica para participar. Os alunos fizeram uma recitação coletiva dos cordéis, em seguida, fizemos um lanche compartilhado.

Como produto final, tivemos a produção de um caderno coletivo com as novas versões dos contos infantis (releitura), estrofes de temas da adolescência e versão digitada dos cordéis, além da exposição das produções aberta a todo corpo escolar.

\section{Considerações finais}

Durante o percurso do trabalho, percebemos que não era tão fácil transformar contos de Clarice em cordel. Nesse aspecto, a pesquisa permitiu compreender que a 
leitura de um texto não é só cópia de palavras, mas um trabalho árduo e contínuo de leitura, compreensão, escrita e reeescrita, que, quando mediado pelo professor, pode gerar bons textos.

Mediante o exposto e por entendermos a importância da leitura de clássicos brasileiros nas aulas de literatura, buscamos desmistificar a construção de julgamentos prévios, relacionados ao texto clássico, realizando atividades que promovessem a formação de um leitor crítico reflexivo, o qual consegue deixar seus "preconceitos" de lado ao entender seus dilemas por meio da conexão entre o cânone e o popular.

Portanto, sentimo-nos motivados a realizar nosso projeto de práticas de oficina de leitura e escrita. Tendo como um dos grandes desafios, instigar nesses jovens a descoberta do conhecimento a partir do prazer pela leitura.

\section{Referências}

ABREU, Márcia (org.). Leitura, história e história da leitura. Campinas, SP: Mercado de Letras; São Paulo: FAPESP, 1999.

BRONCKART, Jean-Paul. Atividade de linguagem, textos e discursos: por um interacionismo sócio-discursivo. São Paulo: EDUC, 2003.

COELHO, Nelly Novaes. Literatura Infantil: teoria, análise, didática. 7. ed. São Paulo. Moderna, 2005.

CHAVES, Otília O. A arte de contar histórias. 3. ed. Rio de Janeiro: Confederação Evangélica do Brasil, 1963.

COSSON, Rildo. Círculos de leitura e letramento literário. São Paulo: Contexto, 2017.

FONSECA, J. J. S. Metodologia da pesquisa científica. Fortaleza: UEC, 2002.

LISPECTOR, Clarisse. Onde estivestes de noite. São Paulo: Rocco, 1999.

Outros escritos. Rio de Janeiro: Rocco, 2005.

MARINHO, Ana Cristina. O cordel no cotidiano escolar. São Paulo: Cortez, 2012. 
NOGUEIRA, Carlos. Introdução à literatura de cordel portuguesa. Porto: Edições Lusitânia, 2002.

PINTO, Maria do Rosário. Catalogação de folhetos de cordel. Rio de Janeiro: Funarte, CNFCP, 2002.

ROULET, E. La description de l'organisation du discours. Du dialogue au texte. Paris: Didier, 1999.

SOLÉ, Isabel, Estratégias de Leitura. Tradução Cláudia Schilling. 6. ed. Porto Alegre: Artmed, 2009.

THIOLENT, M. Metodologia da pesquisa-ação. São Paulo: Cortez, 1992.

TODOROV, Tzvetan. A literatura em perigo. Rio de Janeiro: DIFEL, 2009.

Recebido em 4 de maio de 2019.

Aceite em 17 de junho de 2019. 